\title{
Diagnostic Value of Ultrasonography in Patients Suspected Acute Appendicitis
}

\section{Elahifar $\mathrm{M} \mathrm{A}^{1}$, Taheri $\mathbf{H}^{2}$, Bighamian $\mathrm{A}^{3}$}

\author{
${ }^{1}$ Staff of Radiology, ${ }^{2}$ Resident of Radiology, ${ }^{3}$ Resident of Radiology, Zahedan University of \\ Medical Sciences, Iran
}

\begin{abstract}
Introduction: Appendectomy is one of the most frequently performed abdominal operations in surgical practice. Preoperative imaging has been demonstrated to improve diagnostic accuracy in appendicitis. Abdominal ultrasonography (US) is the most commonly and firstline imaging modality used for diagnosing acute appendicitis (AA).The aim of this study was to demonstrate the diagnostic value of abdominal ultrasonography for diagnosing acute appendicitis. Methods: In a retrospective study, we analyzed 200 consecutive patients with abdominal pain that undergoing appendectomy, from June 2009 to April 2012. Patient characteristics, preoperative ultrasonography (US) and laboratory assessment including WBC were collected. Final diagnosis of appendicitis was confirmed by histopathological examination. Results were compared with US. Results: Two hundred patients were admitted to this study that undergoing appendectomy. Mean age was 24 years (range: 1 to 91 years), and $57 \%$ were females. Patient White blood cell counts were found to be high in $78 \%$ while it was $86 \%$ for AA group and $64 \%$ for NA group ( $p<0.05)$. One hundred sixty-six of these patients $(83 \%)$ were diagnosed as acute appendicitis on pathology, and $34(17 \%)$ were diagnosed differently. 157 of patients underwent US, eighty two of this patients diagnosed as acute appendicitis on US examinations and in 78 of them were also reported as acute appendicitis on histopathological examination. The sensitivity and specificity of abdominal US for diagnosing appendicitis were $70 \%$ and $90.2 \%$ respectively. Positive predictive value (PPV) was 93\% and negative predictive value (NPV) was reported 62\%. Conclusion: Ultrasonography has a high PPV and specificity, so as a diagnostic tool, positive US strongly suggests the diagnosis of AA. A low negative predictive value recommends that negative US is not sufficient to exclude the diagnosis of AA and patients could not be managed on an outpatient basis following a negative scan.
\end{abstract}

Key words: Acute Appendicitis, Ultrasonography

\section{Introduction}

Acute appendicitis (AA) is one of the most common causes of acute surgical abdomen. ${ }^{1}$ Also Appendectomy is one
Corrospondence to: Hajar Taheri, Resident of Radiology, Zahedan University of Medical Sciences, Iran

E-mail: hajar.taheri@gmail.com 
of the most frequently performed abdominal operations in surgical practice. ${ }^{2}$

The diagnosis of AA is still base on medical history and physical examination ${ }^{3}$ and surgery remains the treatment of choice for AA. ${ }^{4}$

If accurate diagnosis is made in time, AA can be treated easily, otherwise delay in diagnosis and treatment can lead to gangrene perforation and diffuse peritonitis. ${ }^{5}$ Although the rate of unnecessary appendectomies is comparatively high (20-30\%) it is considered acceptable because the rate of perforated appendices is $7-30 \%{ }^{6}$

While AA traditionally is diagnosed clinically, but not all patients present with the classic symptoms. ${ }^{7-9}$ The presence of an atypical clinical picture makes the diagnosis difficult in some patients such as: pediatric; elderly patients; obese; female patients in reproductive age or pregnant and patients with pelvic or retrocecal appendices. ${ }^{3}$ So other supplementary modalities may be necessary to help diagnosing AA. These include the use of clinical scoring system or diagnostic algorithms such as the Alvarado system, serum inflammatory markers, and radiologic imaging. ${ }^{4,7}$

Preoperative imaging has been demonstrated to improve diagnostic accuracy in appendicitis. ${ }^{10}$ More ultrasound (US) and computed tomography (CT) are used to help diagnosing AA. ${ }^{7}$

Abdominal ultrasonography (US) is the most commonly and first-line imaging modality used for diagnosing $\mathrm{AA}^{1}$, as it is widely available and lack of radiation exposure inherent in computed tomography (CT). ${ }^{1,6}$ Also, US is an operator- dependent modality, and the diagnostic values are different in various studies. ${ }^{12}$ The aim of this study was to demonstrate the diagnostic value of abdominal US for diagnose of acute appendicitis.

\section{Methods}

\section{Patients}

In a cross-sectional retrospective study, we collected the data of 200 consecutive patients with abdominal pain that undergoing appendectomy, from June 2009 to April 2012 in Emam Ali Hospital of Zahedan University of Medical Science.

Patients have not Pathology reports of appendices were excluded from the study.

The study was approved by ethical committee and all participants provided written consent.

\section{Data collection and measurements}

For each patient we collected the data including: demographic information (age, sex), history of pain, physical examination, laboratory assessment including WBC, preoperative US, operative findings and pathology report.

Ultrasound was carried out by radiology residents, by the use of high-resolution Bmode ultrasonography (model LOGIC 7; GE) with linear and curved transducers with ultrasound frequencies ranged between 2.5 and $7.5 \mathrm{MHz}$. The diagnostic criteria for acute appendicitis in US including maximum diameter greater than $6 \mathrm{~mm}$, lack of compressibility, hyperemia on Doppler, the presence of free fluid in the right lower quadrant and infiltration of the periappendiceal fat. ${ }^{13-15}$ Sonographic results 
were classified as either "positive" or "negative."

The histopathological diagnosis of acute appendicitis was confirmed by the presence of polymorphonuclear cells in the muscular layer (transmural infiltration) of the appendicular wall. White blood cell count (WBC) higher than $10500 / \mathrm{mm}^{3}$ was accepted as leukocytosis.

\section{Statistical analysis}

Final diagnosis of appendicitis was confirmed by histopathological examination. Results were compared with US. The sensitivity and specificity of all US images were calculated based on the pathology results of the appendectomy. All statistical analysis were performed using SPSS for Windows (version 15.0). P-values less than 0.05 were accepted as significant.

Table 1: Diagnostic Values of the
abdominal ultrasound in acute
appendicitis $(n=200)$.

\begin{tabular}{|lc|}
\hline Value & $\%$ \\
Sensitivity & $70 \%$ \\
Specificity & $90.2 \%$ \\
Positive predictive value & $93 \%$ \\
Negative predictive value & $62 \%$ \\
\hline
\end{tabular}

\section{Results}

200 patients were admitted to this study with abdominal pain that undergoing appendectomy. Patients have not Pathology reports of appendices were excluded from the study.

The mean age of the patient undergoing an appendectomy was 24 years and ages ranged from 1 to 91 years. $29 \%$ of patients were under the 18 years old. We presented 84 male $(42.2 \%)$ and 116 female $(57.8 \%)$.

Patients White blood cell counts were found to be high $(>10500 / \mathrm{mm} 3)$ in $78 \%$ while it was $86 \%$ for AA group and \%64 for NA group $(\mathrm{p}<0.05)$.

One hundred sixty-six of these patients $(83 \%)$ were diagnosed as acute appendicitis on pathology, and $34(17 \%)$ were diagnosed differently. The most differential diagnose was ovarian complications. $5 \%$ of appendix specimens removed were perforated.

153 of patients underwent ultrasonography; eighty two of these patients diagnosed as acute appendicitis on US examinations and in 78 of them were also reported as acute appendicitis on histopathological examination.

A positive US was considered a true positive if the diagnosis of appendicitis was confirmed by histology and a false positive if the specimen showed no features of inflammation. By the same token, a negative US was considered a true negative if the specimen showed no features of inflammation and a false negative if histology confirmed appendicitis.

The sensitivity and specificity of abdominal ultrasonography for diagnosing appendicitis were $70 \%$ and $90.2 \%$ respectively. Positive predictive value (PPV) was 93\% and negative predictive value (NPV) was reported $62 \%$.( Table 1, 2) 


\section{Table 2:}

\begin{tabular}{lccccc}
\hline & $\begin{array}{c}\text { True- } \\
\text { positive }\end{array}$ & $\begin{array}{c}\text { True- } \\
\text { negative }\end{array}$ & $\begin{array}{c}\text { False- } \\
\text { positive }\end{array}$ & $\begin{array}{c}\text { False- } \\
\text { negative }\end{array}$ & Total \\
\hline $\begin{array}{l}\text { Number of } \\
\text { Patient's }\end{array}$ & 82 & 37 & 4 & 34 & 200 \\
\hline
\end{tabular}

A comparison of the US results between genders was made. Among the men, ultrasound diagnosed AA in $68 \%$. In the 74 women it showed a correct diagnosis in $63 \%$. Although US was more accurate in men but there was no significant difference with Chisquare test $(\mathrm{p}=0.12)$.

17 patients of our study were pregnant and in $50 \%$ of them US could not detect AA. It may be due to low accuracy of US in pregnancy for diagnose of AA. 59 of patients were under the 18 years old and US right diagnose of $\mathrm{AA}$ in $60 \%$.

\section{Discussion}

Acute appendicitis (AA) is one of the most commonly diagnosed causes of acute abdomen. ${ }^{4}$

The most important diagnostic tool is still physical examination but recently imaging tools is widely used in the diagnose and differential diagnose of patients with acute abdominal pain. ${ }^{16}$ With developments in diagnostic ultrasonography (US) and CT scan, the diagnostic accuracy of AA has improved from $75 \%$ to $97 \%{ }^{17-19}$

US is part of the diagnostic tools for cause of acute abdomen diagnosis and is relatively inexpensive, safe, and available. US can be performed at the bedside, involves a short acquisition time, does not use ionizing radiation, and may show evidence of other causes of abdominal pain. It is particularly useful in evaluating young women, pregnant patients and children. ${ }^{19}$

In this study all 200 patients were demonstrating positive symptoms and physical signs for appendicitis.

White blood cell counts were high for the $78 \%$ of the patients. Also other studies such as Elangovan et al found high levels of white blood cell count in 80 percent of AA patients. ${ }^{20,}{ }^{21}$ But unfortunately, the white blood cell is elevated in up to 70 percent of patients with other causes of right lower quadrant pain ${ }^{20}$, so it has a low accuracy for differentiation of abdominal pain causes.

We used US for 200 suspicious acute appendicitis patient and found US had a sensitivity of $70 \%$ and a specificity of $90.2 \%$. The positive predictive value of US was $93 \%$ and the negative predictive value of test was $62 \%$.

In another study US had $71.2 \%$ sensitivity, $83.3 \%$ specificity and $72.4 \%$ accuracy. The PPV of US was $97.4 \%$, the NPV was $25 \%$. $^{22}$ 
Scammell et al have shown US as a diagnostic tool for acute appendicitis in children had a sensitivity of $83.3 \%$, a specificity of $97.4 \%$, a PPV of $92.1 \%$ and a NPV of $94.0 \% .{ }^{23}$ This ratios is more than of our results.

Rajeev gave these results at his study on 118 preoperatively US performed appendectomy patients as $63.3 \%, 82.14 \%, 91.93 \%$ and $41.07 \%{ }^{24}$

This variation in result of different studies may be due to some reasons. Previous studies have shown two main factors in practice that significantly influence on US diagnosis of AA ,including the experience of the radiologist, patient factors or technique used. ${ }^{19,25}$

Visualization of a normal appendix is more difficult in patients with a large body habitus. With increase in patient's weight, the detection rate of the appendix is significantly decreases. Accuracy of US also decreases with retrocecal location of the appendix. $^{26}$

17 patients of our study were pregnant and in $50 \%$ of them US could not detect appendicitis. It may be due to low accuracy of US in pregnancy for AA diagnosis.

Whatever, comparing this study with other studies reveals that US provides reliable findings for the diagnosis of acute appendicitis.

In our study the PPV of US was $93 \%$, so as a diagnostic tool, positive US strongly suggests the diagnosis of AA, however in this study, US is done by radiology residents without much experience. We found the
NPV of US was 62\%. A low negative predictive value recommends that patients could not be managed on an outpatient basis following a negative scan.

\section{Conclusion}

Ultrasonography has a high PPV and specificity, so as a diagnostic tool, positive US strongly suggests the diagnosis of AA. A low negative predictive value recommends that negative US is not sufficient to exclude the diagnosis of AA and patients could not be managed on an outpatient basis following a negative scan.

\section{References}

1. Gökçe AH, Aren A, Gökçe FS, Dursun N, Barut AY. Reliability of ultrasonography for diagnosing acute appendicitis. Ulus Travma Acil Cerrahi Derg. 2011 Jan; 17(1):19-22.

2. John SK, Joseph J, Shetty SR. Avoiding negative appendectomies in rural surgical practice: is C-reactive protein estimation useful as a diagnostic tool. Natl Med J India. 2011 May-Jun; 24(3):144-7.

3. Peixoto R, Nunes T, Gomes C. Indices of diagnostic abdominal ultrasonography in acute appendicitis. Influence of gender and physical constitution, time evolution of the disease and experience of radiologist. Rev. Col. Bras. Cir. 2011; 38(2): 105-111.

4. Anielski R, Kuśnierz-Cabala B, Szafraniec K. An evaluation of the utility of additional tests in the preoperative diagnostics of acute appendicitis. Langenbecks Arch Surg 2010; 395: 1061-1068. 
5. Khan S. Elevated serum bilirubin in acute appendicitis :a new diagnostic tool. Kathmandu Univ Med J (KUMJ). 2008 Apr-Jun; 6(2):161-5.

6. Binnebösel M, Otto J, Stumpf $M$, Mahnken AH, Gassler N, Schumpelick V, Truong S. Acute appendicitis. Modern diagnostics--surgical ultrasound. Chirurg. 2009 Jul; 80(7):579-87.

7. Wong K, Cheung T, Tam P. Diagnosing acute appendicitis: are we overusing radiologic investigations? Journal of Pediatric Surgery 2008- 43; 2239-2241.

8. Brender JD, Marcuse EK, Koepsell TD, et al. Childhood appendicitis: factors associated with perforation. Pediatrics 1985;76:301-6.

9. Rothrock SG, Skeoch G, Rush JJ, et al. Clinical features of misdiagnosed appendicitis in children.Ann EmergMed 1991;20:45-50.

10. Poortman P, Oostvogel HJ, Bosma E, Lohle PN, Cuesta MA, de Lange-de Klerk ES, Hamming JF. Improving diagnosis of acute appendicitis: results of a diagnostic pathway with standard use of ultrasonography followed by selective use of CT. J Am Coll Surg. 2009 Mar; 208(3):434-41

11. Butler M,Servaes S, Srinivasan A,Edgar J, Del Pozo G, Darge K. US depiction of the appendix: role of abdominal wall thickness and appendiceal location. Emerg Radiol 2011, 18: 525-531.

12. Chan I, Bicknell SG, Graham M: Utility and diagnostic accuracy of sonography in detecting appendicitis in a community hospital. AJR Am J Roentgenol 2005, 184(6):1809-1812.

13. Van Randen A, Lameris W, van Es HWet al Profiles of US and CT imaging features with a high probability of appendicitis. Eur Radiol.2010;20:16571666.

14. Baldisserotto $\mathrm{M}$, Peletti AB Is colour Doppler sonography a good method to differentiate normal and abnormal appendices in children? Clin Radiol. 2007; 62:365-369.

15. Gutierrez CJ, Mariano MC, Faddis DM et al. Doppler ultrasound accurately screens patients with appendicitis. Am Surg. 1999; 65:1015-1017.

16. Randen A, Laméris W, Wouter van Es $H$,van Heesewijk $H$, van Ramshorst B, ten Hove Wand et all. A comparison of the Accuracy of Ultrasound and Computed Tomography in common diagnoses causing acute abdominal pain. Eur Radiol 2011- 21; 1535-1545.

17. Kirshtein B, Perry Z,Mizrahi S, Lantsberg L. Value of Laparoscopic Appendectomy in the Elderly Patient. World J Surg 2009- 33; 918-922.

18. Lee SL, Walsh AJ, Ho HS Computed tomography and ultrasonography do not improve and may delay the diagnosis and treatment of acute appendicitis. Arch Surg. 2001; 136: 556-562.

19. Pacharn P,Ying J, Linam L,Brody A, Babcock D. Sonography in the Evaluation of Acute Appendicitis. J 
Ultrasound Med 2010; 29:1749-1755.

20. Calder JD, Gajraj H: Recent advances in the diagnosis and treatment of acute appendicitis. Br J Hosp Med 1995, 54:129-133.

21. Nasiri S, Mohebbi F, Sodagari N, Hedayat A. Diagnostic values of ultrasound and the Modified Alvarado Scoring System in acute appendicitis. International Journal of Emergency Medicine 2012; 5:26.

22. Scammell S, Lansdale N, Sprigg A, Campbell D, Marven S. Ultrasonography aids decision-making in children with abdominal pain. Ann R Coll Surg Engl 2011; 93: 405-409.

23. Trout A, Sanchez R, Torres M, Pai D, Strouse P. A critical evaluation of US for the diagnosis of pediatric acute appendicitis in a real-life setting: how can we improve the diagnostic value of sonography. Pediatr Radiol 2012;
42:813-823.

24. Schuh S, Man C, Cheng A et al Predictors of non-diagnostic ultrasound scanning in children with suspected appendicitis. J Pediatr2011; 158:112118.

25. Elangovan S: Clinical and laboratory findings in acute appendicitis in the elderly. J Am Board Fam Pract 1996, 9:75-78.

26. Rajeev S, Kasliwal DK, Sharma RG: Evaluation of negative appendicectomy rate in cases of suspected acute appendicitis and to study the usefulness of ultrasonography in improving the diagnostic accuracy. Indian Journal of Surgery 2007, 69:194-197. 